\title{
Blood-brain transfer of Pittsburgh compound B in humans
}

\author{
Albert Gjedde 1,2,3,45*, Joel Aanerud ${ }^{2}$, Hans Braendgaard ${ }^{6}$ and Anders B. Rodell ${ }^{2}$ \\ ${ }^{1}$ Department of Neuroscience and Pharmacology, University of Copenhagen, Copenhagen, Denmark \\ 2 Department of Nuclear Medicine and PET Centre, Aarhus University Hospital, Aarhus, Denmark \\ ${ }^{3}$ Center of Functionally Integrative Neuroscience, Faculty of Health, Aarhus University, Aarhus, Denmark \\ ${ }^{4}$ Department of Neurology, McGill University, Montreal, QC, Canada \\ ${ }^{5}$ Department of Radiology and Radiological Science, Johns Hopkins University, Baltimore, MD, USA \\ ${ }^{6}$ Department of Neurology, Aarhus University Hospital, Aarhus, Denmark
}

\section{Edited by:}

Hari S. Sharma, Uppsala University, Sweden

\section{Reviewed by:}

Eugene A. Kiyatkin, National

Institute on Drug Abuse, USA

Jose-Vicente Lafuente, University of

Basque Country (UPV-EHU), Spain

\section{*Correspondence:}

Albert Gjedde, Department of Neuroscience and Pharmacology,

Panum Institute, 33.3.6,

Blegdamsvej 3B, 2200 Copenhagen

N., Denmark

e-mail: gjedde@sund.ku.dk
In the labeled form, the Pittsburgh compound B $\left(2-\left(4^{\prime}-\left\{N-m e t h y l-\left[{ }^{11} \mathrm{C}\right]\right\}\right.\right.$ methyl-aminophenyl)-6-hydroxy-benzothiazole, $\left.\left[{ }^{11} \mathrm{C}\right] \mathrm{PiB}\right)$, is used as a biomarker for positron emission tomography (PET) of brain $\beta$-amyloid deposition in Alzheimer's disease (AD). The permeability of $\left[{ }^{11} \mathrm{C}\right] \mathrm{PiB}$ in the blood-brain barrier is held to be high but the permeability-surface area product and extraction fractions in patients or healthy volunteers are not known. We used PET to determine the clearance associated with the unidrectional blood-brain transfer of $\left[{ }^{11} \mathrm{C}\right] \mathrm{PiB}$ and the corresponding cerebral blood flow rates in frontal lobe, whole cerebral cortex, and cerebellum of patients with Alzheimer's disease and healthy volunteers. Regional cerebral blood flow rates differed significantly between the two groups. Thus, regional and whole-brain permeability-surface area products were identical, in agreement with the observation that numerically, but insignificantly, unidirectional blood-brain clearances are lower and extraction fractions higher in the patients. The evidence of unchanged permeability-surface area products in the patients implies that blood flow changes can be deduced from the unidirectional blood-brain clearances of $\left[{ }^{11} \mathrm{C}\right] \mathrm{PiB}$ in the patients.

Keywords: Alzheimers disease, blood-brain barrier, cerebral blood flow measurement, permeability-surface area product, pittsburgh compound B

\section{INTRODUCTION}

The amyloid cascade is the leading current explanation of the etiology of Alzheimer's disease (AD) (Hardy and Selkoe, 2002; Jack et al., 2010). The hypothesis holds that amyloid- $\beta$ (A $\beta$ ) has a primary role in the biochemical, histological, and pathological changes that happen in the brain when $\mathrm{AD}$ evolves. In this process, the deposition of $A \beta$ is considered an early event, which implies that biomarkers of $A \beta$ may detect the presence of disease at the earliest stages of onset (McKhann et al., 2011).

Modification of the amyloid-binding dye thioflavin-T made non-invasive PET imaging possible with the labeled form of the Pittsburgh compound $\mathrm{B}$, the tracer $\left[{ }^{11} \mathrm{C}\right] \mathrm{PiB}$. Although other tracers currently are under evaluation (Wong et al., 2013), $\left[{ }^{11} \mathrm{C}\right] \mathrm{PiB}$ is the most extensively examined marker of $\mathrm{A} \beta$ in human studies with PET (Klunk et al., 2004; Price et al., 2005; Mintun et al., 2006; Lockhart et al., 2007; Ikonomovic et al., 2008). Compared to cognitively intact controls, AD patients exhibit greater $\left[{ }^{11} \mathrm{C}\right] \mathrm{PiB}$ retention in areas known to have high $A \beta$ deposits such as the frontal and parietal cortices, whereas brain areas relatively unaffected by $A \beta$ pathology, such as the cerebellum, show equivalently modest $\left[{ }^{11} \mathrm{C}\right] \mathrm{PiB}$ retention (Klunk et al., 2004; Price et al., 2005; Ikonomovic et al., 2008). However, the specific transport and binding properties of $\left[{ }^{11} \mathrm{C}\right] \mathrm{PiB}$ remain uncertain when the tracer passes from the circulation into the tissue of the brain.
Klunk et al. (2004) compared the brain uptake of $\left[{ }^{11} \mathrm{C}\right] \mathrm{PiB}$ with the uptake of fluorine-18-labeled fluorodeoxyglucose $\left(\left[{ }^{18} \mathrm{~F}\right] \mathrm{FDG}\right)$, a marker of glucose consumption in brain of patients with Alzheimer's disease. The authors found that $\left[{ }^{11} \mathrm{C}\right] \mathrm{PiB}$ retention at late times correlated inversely with cerebral glucose metabolism traced by $\left[{ }^{18} \mathrm{~F}\right] \mathrm{FDG}$. In the brain of patients with $\mathrm{A} \beta$ deposits, compared to patients without $A \beta$ deposits, significant $\left[{ }^{11} \mathrm{C}\right] \mathrm{PiB}$ retention correlated well with variable levels of amyloid deposition, as determined by later postmortem analysis (Klunk et al., 2004). However, at earlier circulation times, Rostomian et al. (2011) found comparable $\left[{ }^{11} \mathrm{C}\right] \mathrm{PiB}$ and $\left[{ }^{18} \mathrm{~F}\right] \mathrm{FDG}$ uptakes in patients, consistent with substantial initial clearance of $\left[{ }^{11} \mathrm{C}\right] \mathrm{PiB}$ from brains of patients, as also found in brains of healthy control subjects studied by Blomqvist et al. (2008). These results indicate that the phases of initial uptake and subsequent retention of $\left[{ }^{11} \mathrm{C}\right] \mathrm{PiB}$ differ in human brain, with initial deposit of $\left[{ }^{11} \mathrm{C}\right] \mathrm{PiB}$ limited by delivery and hence also by cerebral blood flow, coupled to metabolism, and later retention limited by binding to tissue components such as $\mathrm{A} \beta$ (Forsberg et al., 2012).

To determine the extent to which the initial uptake of $\left[{ }^{11} \mathrm{C}\right] \mathrm{PiB}$ is flow-limited, and to convert the clearance to a measure of permeability, it is necessary to compute the permeability-surface area products of microvascular transport of $\left[{ }^{11} \mathrm{C}\right] \mathrm{PiB}$ in different brain regions, as well as the fractions of extracted $\left[{ }^{11} \mathrm{C}\right] \mathrm{PiB}$. To obtain these values, we must know the values of the cerebral 
blood flow $(\mathrm{CBF})$ that delivers $\left[{ }^{11} \mathrm{C}\right] \mathrm{PiB}$ to brain tissue. Here, to test the hypothesis of initial flow-limited brain uptake of $\left[{ }^{11} \mathrm{C}\right] \mathrm{PiB}$ in humans, we determined $\mathrm{CBF}$ values and $\left[{ }^{11} \mathrm{C}\right] \mathrm{PiB}$ uptake in five patients with $\mathrm{AD}$, and six age-matched healthy volunteers, by means of PET.

\section{METHODS}

\section{SUBJECTS}

Five patients with $\mathrm{AD}$ (3 women, 2 men) with an average age of $64(S D=7)$ years and moderately reduced Mini-mental State Examination (MMSE) scores of 22-25 volunteered to complete the tomography. The patients were recruited by the local Dementia Clinic and screened by an experienced neurologist for the presence of definite Dementia of Alzheimer's Type (DAT). Six healthy age-matched HC volunteers with MMSE scores in the range of $28-30$ with a mean age of $70(S D=5)$ years served as controls, recruited by public advertisement and screened with clinical, neurological, and neuropsychological testing including MMSE adapted to Danish (Lolk et al., 2000) to exclude cognitive impairment. We obtained written informed consent from all subjects to the protocols approved by the Regional Science Ethics Committee in accordance with the Declarations of Helsinki. We previously reported PET results from the same five patients and from eight healthy volunteers, including the six healthy volunteers studied here (Rodell et al., 2012). We were unable to include two of the healthy volunteers because arterial samples of $\left[{ }^{11} \mathrm{C}\right] \mathrm{PiB}$ concentration were unavailable.

\section{POSITRON EMISSION TOMOGRAPHY Image acquisition}

All subjects had positron emission recordings, one or two with $\left[{ }^{15} \mathrm{O}\right]$ water and one with $\left[{ }^{11} \mathrm{C}\right] \mathrm{PiB}$, in the $3 \mathrm{D}$ mode of the ECAT High Resolution Research Tomograph (HRRT, CTI/Siemens, Knoxville, TN, USA) in a quiet room with the subjects resting in a supine position with eyes open. The images were reconstructed with three-dimensional ordinary Poisson ordered subset expectation maximization (3D-OP-OSEM) point spread function reconstruction (Varrone et al., 2009), using 10 iterations and 16 subsets with FWHM at approximately $1.5 \mathrm{~mm}$. The reconstructed images were corrected for random and scatter events, detector efficiency variations, and dead time. Tissue attenuation scans were performed using a rotating $68 \mathrm{Ge}$ source. Dynamic emission recordings lasting $3 \mathrm{~min}$ ( 21 frames), or $90 \mathrm{~min}$ (30 frames) were initiated upon bolus intravenous injection of $\left[{ }^{15} \mathrm{O}\right]$ water $(500 \mathrm{MBq})$ or $\left[{ }^{11} \mathrm{C}\right] \mathrm{PiB}(500 \mathrm{MBq})$, respectively. Catheters (Artflon and Venflon, Becton Dickinson, Swindon, UK) were inserted in the right radial artery and left cubital vein. For the $\left[{ }^{15} \mathrm{O}\right]$ water sessions, arterial blood radioactivity was measured every half second for the duration of the PET scan by an automated blood sampling system (Allogg AB, Mariefred, Sweden), cross-calibrated with the tomograph, and then corrected for external delay and dispersion. For the $\left[{ }^{11} \mathrm{C}\right] \mathrm{PiB}$ sessions, arterial blood radioactivity was measured in blood samples drawn manually for the duration of the tomography session. For anatomical orientation, highresolution T1-weighted MR images were obtained at 1.5 or $3 \mathrm{~T}$ (GE Sigma Systems).

\section{Image registration and segmentation}

The summed emission recordings of $\left[{ }^{15} \mathrm{O}\right]$ water and $\left[{ }^{11} \mathrm{C}\right] \mathrm{PiB}$ were automatically co-registered to the individual MRI scans using a 6 parameter affine transformation. Individual MR images initially were co-registered to a common stereotactic space (Montreal Neurological Institute) (Collins and Evans, 1997), using a 12-parameter affine rigid body transformation, and subsequently non-linearly transformed. After the calculation of the final PET-Talairach transformation matrix, dynamic emission recordings were re-sampled into common coordinates. Regional $\mathrm{CBF}$ and $\mathrm{PiB}$ permeability measures (see below) were obtained from parametric PET image maps using standard model based segmentation (Collins and Evans, 1997) into regions that included frontal lobe (FL), cerebral cortex (CTX), and cerebellum gray matter (CERB).

\section{CALCULATION OF CEREBRAL BLOOD FLOW}

We quantified the CBF as the water clearance $K_{1}^{\mathrm{H}_{2} \mathrm{O}}$ in units of $\mathrm{mL} / 100 \mathrm{~g} / \mathrm{min}$ with the linearized two-compartment model (Blomqvist, 1984) modification of Ohta et al. (1996) and the Lawson-Hanson non-negative least squares solution to general least squares functions (Lawson and Hanson, 1974).

\section{CALCULATION OF BLOOD-BRAIN TRANSFER CONSTANTS OF PiB UPTAKE \\ Unidirectional blood-brain clearance}

We analyzed the uptake of $\left[{ }^{11} \mathrm{C}\right] \mathrm{PiB}$ by means of multilinear graphical analysis (Gjedde, 1981, 1982; Patlak et al., 1983). From the time-radioactivity records in arterial blood samples and brain tissue, we constructed two derived variables, the dependent variable $V(T)$ and the independent variable $\Theta(T)$, according to the principles of the Gjedde-Patlak Plot, as expanded by Gjedde and Wong (2001). The two variables are the time-dependent apparent volume of distribution,

$$
V(T)=\frac{m(T)}{c_{a}(T)}
$$

and the apparent time of accumulation,

$$
\Theta(T)=\frac{\int_{o}^{T} c_{a}(t) d t}{\mathcal{c}_{a}(T)}
$$

which are related by the four parameters of the threecompartment model of irreversible accumulation, the net clearance $K$, the unidirectional clearance $K_{1}$, the dynamic volume of the precursor compartment $V_{g}$, and the dynamic volume of the vascular compartment $V_{o}$,

$$
V(T)=K \Theta(T)+V_{g}\left(1-e^{-\left(K_{1}-K\right) \Theta(T) / V_{g}}\right)+V_{o}
$$

that for a simple reversible exchange between the vascular compartment and a single tissue compartment, for which $K=$ $0\left(k_{3}=0\right)$, reduces to,

$$
V(T)=V_{g}\left(1-e^{-K_{1} \Theta(T) / V_{g}}\right)+V_{o}
$$


used here to obtain the estimates of the unidirectional clearance $K_{1}$, because the regression of the complete equation (3) yielded estimates of $K$ that were not significantly different from zero. At early times $(\Theta(T) \rightarrow 0) V(T)$ approaches the linear relationship (Gjedde, 1981),

$$
V(T) \rightarrow K_{1} \Theta(T)+V_{o}
$$

\section{Permeability and extraction fraction}

The values of cerebral blood flow $(F)$, unidirectional clearance $\left(K_{1}\right)$, and permeability-surface area product $(P S)$ are related by the formula (Crone, 1963, 1965; Gjedde and Christensen, 1984),

$$
K_{1}=F\left(1-e^{-P S / F}\right)
$$

which yields the extraction fraction as the ratio between the unidirectional clearance and the blood flow,

$$
E=K_{1} / F=1-e^{-P S / F}
$$

from which derives the permeability-surface area product,

$$
P S=-F \ln (1-E)
$$

\section{RESULTS}

\section{ARTERIAL PLASMA CONCENTRATIONS}

We normalized the arterial plasma concentrations of $\left[{ }^{11} \mathrm{C}\right] \mathrm{PiB}$ to the area under the curve, as shown in Figure 1. The concentrations revealed a triphasic time course, with an initial rapid rise to a common peak within a minute of administration, an immediate decline to a plateau at $4 \mathrm{~min}$, maintained at about $10 \%$ of the peak activity until the end of sampling at $90 \mathrm{~min}$. The plateau represents metabolites of $\left[{ }^{11} \mathrm{C}\right] \mathrm{PiB}$, appearing in significant amounts after about $4 \mathrm{~min}$ of circulation of the tracer, as shown in Figure 1. When the arterial samples are corrected for the metabolite fractions determined by Lopresti et al. (2005), the unchanged tracer $\left[{ }^{11} \mathrm{C}\right] \mathrm{PiB}$ had declined to less than $3 \%$ of the peak activity by $10 \mathrm{~min}$ after the administration, and to $1 \%$ by $15 \mathrm{~min}$, indicating that the tracer practically had disappeared from the circulation at that time.

\section{BRAIN TIME-ACTIVITY CURVES}

The time-activity curves of the three brain regions selected for the two groups of subjects indicate rapid uptake of $\left[{ }^{11} \mathrm{C}\right] \mathrm{PiB}$, which peaks at approximately $2 \mathrm{~min}$, and subsequent more or less rapid washout from about $4 \mathrm{~min}$ onwards, as shown for the individual subjects in Figure 2, and for the averages in Figure 3, superimposed on the average arterial concentration curves.

\section{MULTITIME GRAPHICAL ANALYSIS}

The multitime graphical analysis (MTGA) or Gjedde-Patlak plots according to equations (1) and (2) show the clear effect of the generation of metabolites of $\left[{ }^{11} \mathrm{C}\right] \mathrm{PiB}$ that do not enter brain tissue, with rapid reduction of the apparant volume of distribution of $\left[{ }^{11} \mathrm{C}\right] \mathrm{PiB}$ in brain tissue as a result, as shown in Figure 4. For this reason, we limited the period of analysis of blood-brain transfer of $\left[{ }^{11} \mathrm{C}\right] \mathrm{PiB}$ to the period $0-4 \mathrm{~min}$, when the generation of metabolites was negligible. The MTGA plots for the time periods $0-4 \mathrm{~min}$ are shown for patients and control subjects in Figure 5, in which the regression curves are shown. When analyzed according to equation (4), the regression yielded consistent estimates of the four parameters of equation (3), with values of $K$ close to zero, indicating single tissue compartment kinetics $\left(k_{3} \cong 0\right)$ according to equation (4). With the value of $K$ fixed at zero, the analysis yielded the estimates of $K_{1}, V_{g}$, and $V_{o}$, shown in Figure 6, together with the estimated values of cerebral blood flow in the same regions. While the regional CBF values differed significantly between the two groups, the unidirectional clearances numerically varied in the same direction as the blood flow values but the differences were not significant.

\section{PERMEABILITY-SURFACE AREA PRODUCTS}

We used the estimates of unidirectional clearance and cerebral blood flow to calculate the extraction fractions and permeability-surface area products of $\left[{ }^{11} \mathrm{C}\right] \mathrm{PiB}$ according to equations (7) and (8), as listed in Table 1 and shown in Figure 6. The values of the PS-products were lower than the CBF values

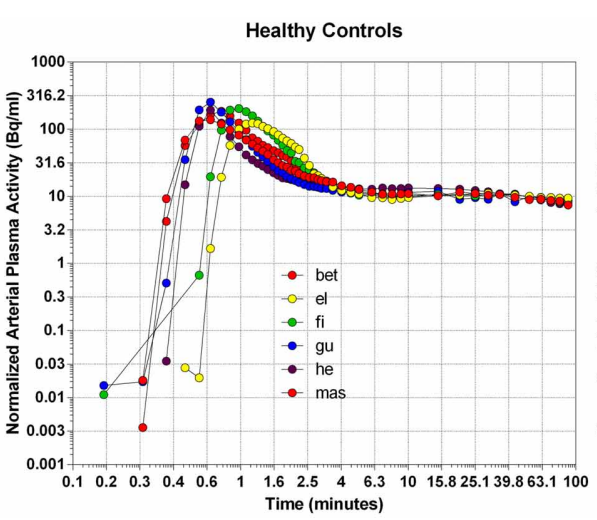

FIGURE 1 | The distributions of arterial plasma concentrations in healthy volunteers (left panel) and patients with Alzheimer's disease (right panel), normalized to average Area

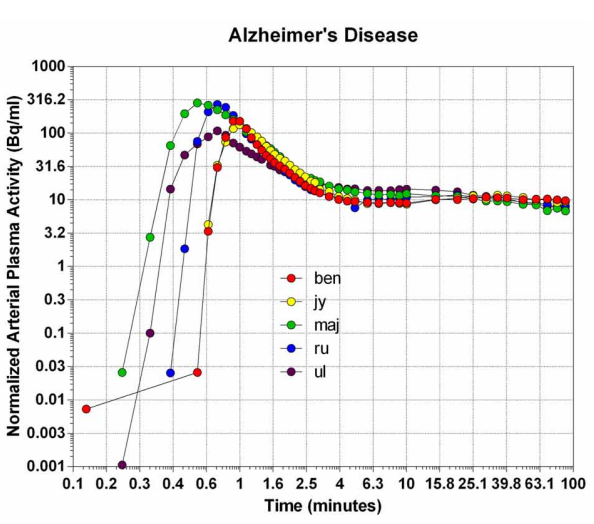

Under Curve (AUC). Abscissa: Log10 rescaling of Time (minutes). Ordinate: Log10 rescaling of average normalized arterial plasma radioactivity. 

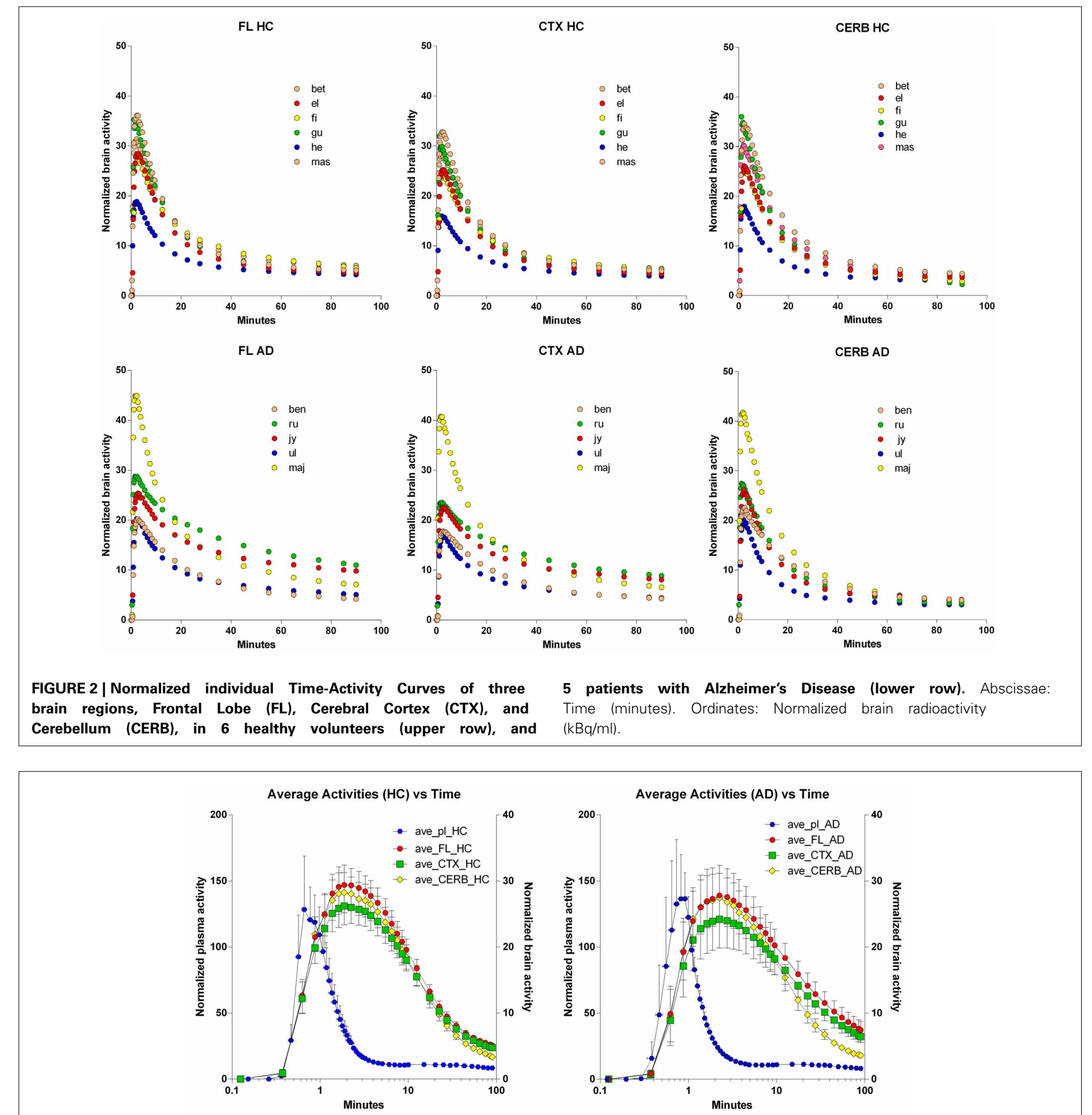

FIGURE 3 | Average regional brain Time-Activity Curves superimposed on average arterial concentration curves. Left panel: Healthy volunteers. Right panel: Patients with Alzheimer's disease.

and varied among regions, but the regional values did not differ significantly between the two groups.

\section{DISCUSSION}

In previous publications, we determined the variability of cerebral blood flow rates in patients with Alzheimer's disease (Rodell et al.,
Abscissae: Time (minutes, log10 scale). Left ordinates: Average normalized plasma activity (kBq/ml). Right ordinates: Average normalized brain activity $\left(\mathrm{kBq} / \mathrm{cm}^{3}\right)$.

2012), and we determined the accumulation of tracer $\left[{ }^{11} \mathrm{C}\right] \mathrm{PiB}$ in regions of the brains of the same patients in relation to cerebral blood flow, compared to healthy control subjects.

The issue resolved in the present report is the question of whether $\left[{ }^{11} \mathrm{C}\right] \mathrm{PiB}$ uptake into the brains of these patients and healthy volunteers during the early phase of blood-brain transfer 


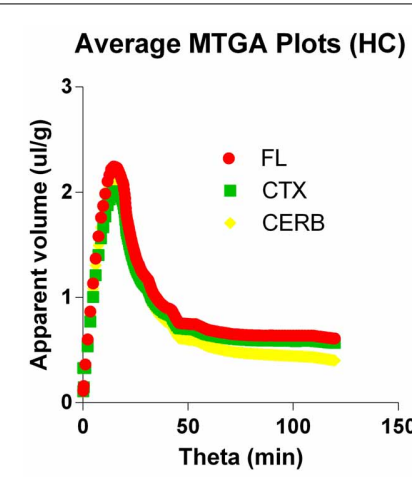

Average MTGA Plots (AD)

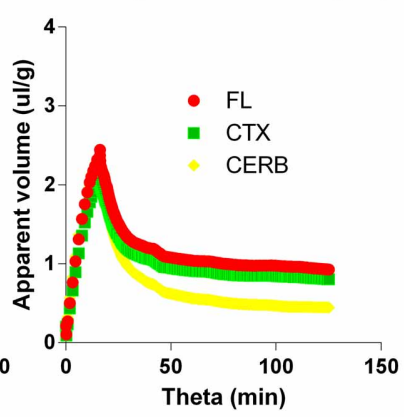

FIGURE 4 | Multitime graphical analysis (MTGA) plots of blood-brain transfer of $\left[{ }^{11} \mathrm{C}\right] \mathrm{PiB}$ according to Equations (1) and (2). MTGA plots reveal effect of generation of metabolites that do not enter brain tissue and disappearance of $\left[{ }^{11} \mathrm{C}\right] \mathrm{PiB}$ from circulation, with rapid reduction of apparent volume of distribution $\left[{ }^{11} \mathrm{C}\right] \mathrm{PiB}$ in brain after 4 minutes of circulation, corresponding to $10 \mathrm{~min}$ in units of normalized time. Left panel: Healthy volunteers. Right panel: Patients with Alzheimer's disease. Abscissae: Normalized time (minutes). Ordinates: Apparent volume of distribution $\left(\mathrm{ml} / \mathrm{cm}^{3}\right)$.
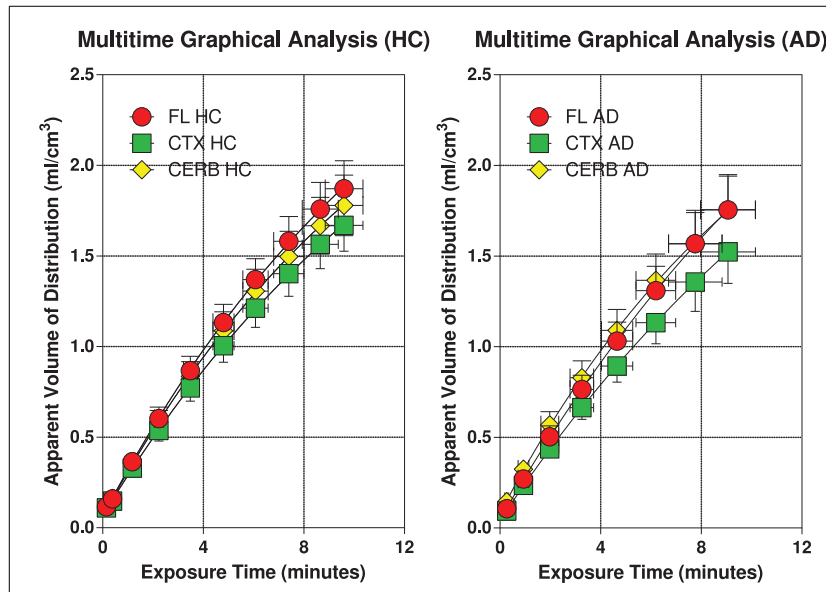

FIGURE 5 | Individual MTGA or Gjedde-Patlak plots with regression curves according to Equations (1) and (2) for 6 healthy volunteers (left panel), and 5 patients with Alzheimer's disease (right panel).

Abscissae: Exposure or 'Theta' (defined in Equation 2) ("normalized") time (minutes). Ordinates: Apparent volume of distribution $\left(\mathrm{ml} / \mathrm{cm}^{3}\right)$.

is flow-limited such that the initial uptake of $\left[{ }^{11} \mathrm{C}\right] \mathrm{PiB}$ can be used reliably as a marker of blood flow. The evidence from the study supports the claim that $\left[{ }^{11} \mathrm{C}\right] \mathrm{PiB}$ uptake during the first $4 \mathrm{~min}$ of circulation is not completely flow-limited, consistent with substantial but not unlimited permeability in the cerebral vasculature of patients with Alzheimer's disease and healthy control subjects. The PS-products were less than the values of cerebral blood flow, establishing unidirectional extraction fraction values at 0.63 or less. A tracer with this property yields flow values that are lower than the true values, and the flow fluctuations are attenuated. Thus, the estimated PSproducts may not be sufficiently high to secure unidirectional clearance rates that always differ significantly when blood flow rates decline.

The search for tracers with initial flow-limited uptake sufficient to accurately estimate blood flow rates has been ongoing for a long time. The issue always concerned the duration of the flow-limited accumulation, and the determination of the moment when the accumulation effectively turns from flow-limitation to significant limitation by diffusion, binding, or metabolism. This transition happens for all tracers, given enough time. The use of the marker to trace blood flow therefore is limited to the period before the transition.

The determination of the brain's microvascular PS-products rests on the measure of the marker's initial clearance, here symbolized by the term $K_{1}$, as shown in Figure 7, displaying both the initial idealized clearance, as derived from the actual uptake of $\left[{ }^{11} \mathrm{C}\right] \mathrm{PiB}$ into the frontal lobe of a healthy volunteer. Judging from this graph, $\left[{ }^{11} \mathrm{C}\right] \mathrm{PiB}$ uptake into brain tissue is effectively unidirectional for only a few minutes after administration the tracer. The accurate determination of this initial clearance is aided by regression to the measured monoexponential approach to a steady-state volume of distribution.

In previous attempts to obtain blood-brain clearance measures of $\left[{ }^{11} \mathrm{C}\right] \mathrm{PiB}$, the authors generally concluded that clearances and hence uptake rates are "high" but values of permeability-surface areas were not reported (Blomqvist et al., 2008; Rostomian et al., 2011), although Blomqvist et al. did obtain unidirectional clearance estimates. Blomqvist et al. (2008) assumed continuous steady-state accumulation of $\left[{ }^{11} \mathrm{C}\right] \mathrm{PiB}$ in brain tissue, for which there is little evidence. The issue reflects the uncertainty of the number of compartments of $\left[{ }^{11} \mathrm{C}\right] \mathrm{PiB}$ distribution in brain tissue that separately and significantly can be identified kinetically. The present analysis gave no evidence of continuous steady-state accumulation of $\left[{ }^{11} \mathrm{C}\right] \mathrm{PiB}$ or its labeled metabolites in brain tissue and instead reflected the kinetics of a single tissue compartment.

There is no strongly correlated decline of brain energy metabolism and cerebral blood flow rates in healthy aging (Aanerud et al., 2012). Neurodegeneration, on the other hand, such as Alzheimer's disease, generally presents with declines of both variables in specific parts of the brain, most likely driven by the reduced energy turnover in these same parts of the brain of demented individuals (Johannsen et al., 2000; Rodell et al., 2012). The unidirectional blood-brain clearance term $K_{1}$ is an expression of the unidirectional influx of $\left[{ }^{11} \mathrm{C}\right] \mathrm{PiB}$ and as such is related to the blood flow rate by means of equation (6). Therefore, we expected to find a correlation between blood flow estimates and $\left.{ }^{11} \mathrm{C}\right] \mathrm{PiB}$ accumulation in the first tomography frames of $\left[{ }^{11} \mathrm{C}\right] \mathrm{PiB}$ uptake. This expectation was supported by the inverse correlation between blood flow and $\left[{ }^{11} \mathrm{C}\right] \mathrm{PiB}$ accumulation in the last tomography frames, as evidence of the presence of $A \beta$ plaques in the tissue. Indeed, blood flow and $\left[{ }^{11} \mathrm{C}\right] \mathrm{PiB}$ accumulation at that time were highly correlated $\left(R^{2}=0.999 ; P=\right.$ $0.021)$.

To convert estimates of unidirectional clearance to blood flow values, the extraction fraction must be known, according to 

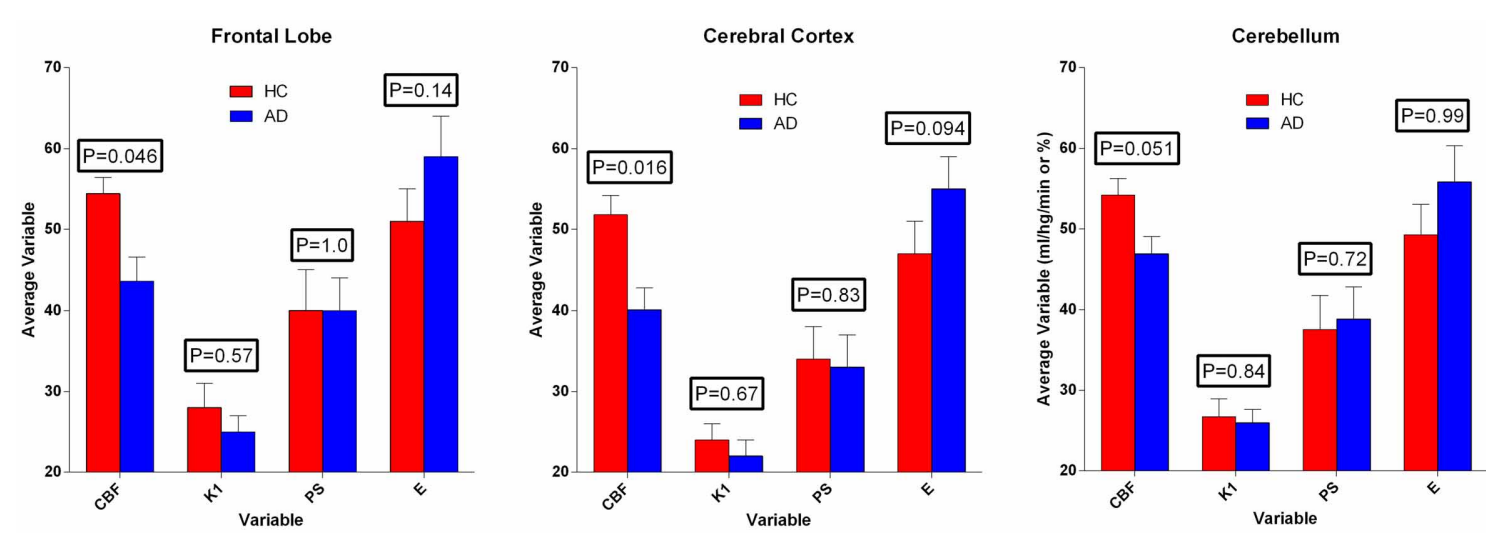

FIGURE 6 | Average estimates ( \pm SEM) of cerebral blood flow and unidirectional clearance, and the calculated values of extraction fraction and permeability-surface area product of $\left[{ }^{11} \mathrm{C}\right] \mathrm{PiB}$, according to Equations
(7) and (8). Values of CBF exceeded values of PS-products, which in turn varied among regions, but did not differ significantly between the two groups. Ordinates: Units of flow ( $\mathrm{ml} \mathrm{g}^{-1} \mathrm{~min}^{-1}$ ) and extraction percentage (\%).

Table 1 | Average estimates $\left( \pm\right.$ SEM) of unidirectional blood-brain clearance $\left(K_{1}\right)$, extraction percentage $(E)$, and permeability-surface area product $(P S)$ in regions of brain of healthy control subjects $(\mathrm{HC})$ and patients with Alzheimer's disease (AD).

\begin{tabular}{|c|c|c|c|c|c|c|c|c|c|c|}
\hline \multirow[t]{2}{*}{ Variable } & \multirow[t]{2}{*}{ Unit } & \multicolumn{3}{|c|}{ Frontal lobe } & \multicolumn{3}{|c|}{ Cortex } & \multicolumn{3}{|c|}{ Cerebellum } \\
\hline & & $\begin{array}{l}\mathrm{HC} \\
(n=6)\end{array}$ & $\begin{array}{l}\text { AD } \\
(n=5)\end{array}$ & $\boldsymbol{P}$ & $\begin{array}{l}\mathrm{HC} \\
(n=6)\end{array}$ & $\begin{array}{l}\text { AD } \\
(n=5)\end{array}$ & $\boldsymbol{P}$ & $\begin{array}{l}\mathrm{HC} \\
(n=6)\end{array}$ & $\begin{array}{l}\text { AD } \\
(n=5)\end{array}$ & $\boldsymbol{P}$ \\
\hline$F$ & $\mathrm{ml} \mathrm{hg^{-1 }} \min ^{-1}$ & $54 \pm 2$ & $43 \pm 3$ & 0.046 & $52 \pm 2$ & $40 \pm 3$ & 0.016 & $54 \pm 2$ & $47 \pm 2$ & 0.051 \\
\hline$K_{1}$ & $\mathrm{ml} \mathrm{hg^{-1 }} \min ^{-1}$ & $28 \pm 3$ & $25 \pm 2$ & 0.57 & $24 \pm 2$ & $22 \pm 2$ & 0.67 & $27 \pm 2$ & $26 \pm 2$ & 0.84 \\
\hline$E$ & $\%$ & $51 \pm 4$ & $59 \pm 5$ & 0.14 & $47 \pm 4$ & $55 \pm 4$ & 0.094 & $49 \pm 4$ & $56 \pm 4$ & 0.99 \\
\hline$P S$ & $\mathrm{ml} \mathrm{hg^{-1 }} \min ^{-1}$ & $40 \pm 5$ & $40 \pm 4$ & 1.0 & $34 \pm 4$ & $33 \pm 4$ & 0.83 & $38 \pm 4$ & $39 \pm 4$ & 0.72 \\
\hline
\end{tabular}

P-values indicate probability of insignificant difference, with correction for multiple comparisons.

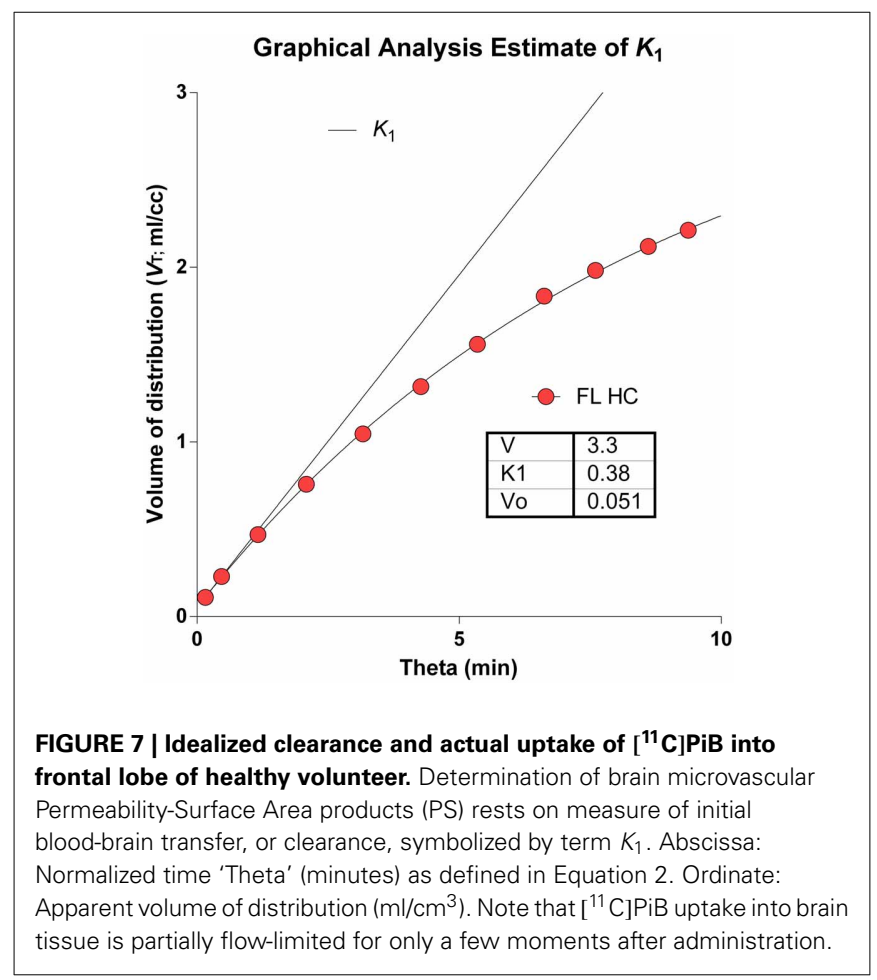

the equation, $F=K_{1} / E$. In the present study, the unidirectional extraction fraction averaged 0.53 for all subjects and regions, but differed significantly between the patients and the healthy control subjects. In a companion study, we used the unidirectional clearance and estimates of PS products to make accurate predictions of blood flow that correlated well with actual CBF measures. With an average extraction fraction of 0.53 , the values of blood flow calculated from the unidirectional clearance respectively over- and underestimated the CBF values determined with labeled water in patients and healthy control subjects and did not differ significantly on average.

No non-gaseous cerebral blood flow indicator is fully extracted. Depending on the distribution volume, a quantity of tracer always remains in the vascular bed, implying that there is no perfect single compartment modeling that fully describes the kinetics (Ohta et al., 1992, 1996). The conversion of non-gaseous tracer uptake therefore depends on the validity of the extraction fraction used to calculate the blood flow from the unidirectional blood-brain clearance, determined kinetically or graphically. The extraction fractions for typical non-gaseous blood flow indicators vary from more than $90 \%$ for ethanol, iodoantipyrine, and butanol, to less than $90 \%$ for antipyrine and water (Gjedde et al., 1975, 1980; Sakurada et al., 1978). The lower the extraction fraction, the more the calculation itself depends on the unknown blood flow. 


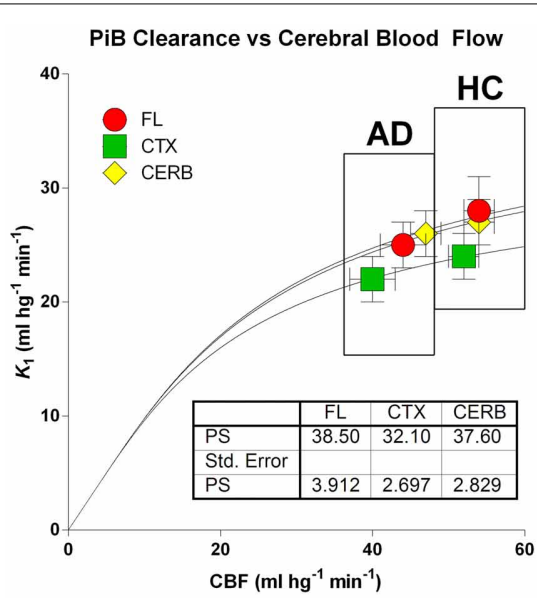

FIGURE 8 | Relations among clearance (left panel) and extraction fraction (right panel) estimates and measured cerebral blood flow values in patients and healthy control subjects according to equations (6) and (7). Abscissae: Cerebral Blood Flow estimates ( $\mathrm{ml} \mathrm{hg}^{-1} \mathrm{~min}^{-1}$ ).

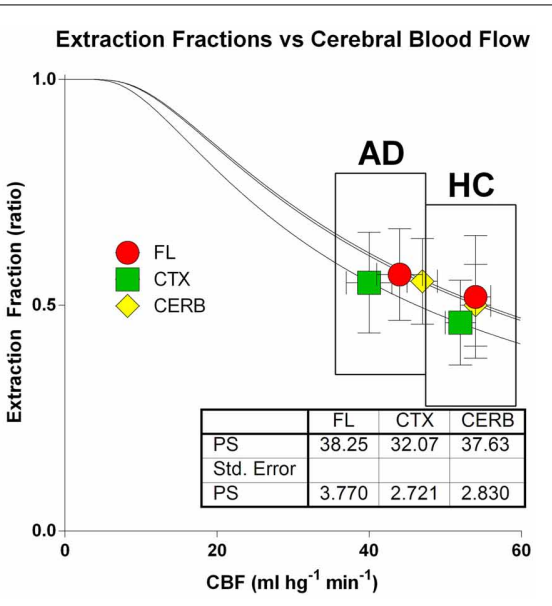

Ordinate (left panel): Unidirectional [ $\left.{ }^{11} \mathrm{C}\right] \mathrm{PiB}$ Clearance $\left(\mathrm{ml} \mathrm{hg}{ }^{-1} \mathrm{~min}^{-1}\right)$. Ordinate (right panel): Extraction fraction (ratio). Similar regional PS-products in the two groups explain numerically attenuated and insignificant differences of unidirectional clearances and extraction fractions.

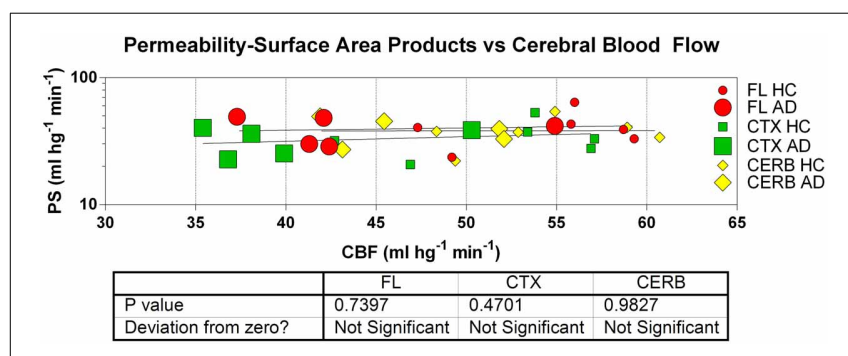

FIGURE 9 | Estimates of permeability-surface area (PS) products reveal no relation to measures of cerebral blood flow (CBF) in frontal lobe (FL), cerebral cortex (CTX), and cerebellum (CERB) of patients and healthy control subjects. Abscissa: $\mathrm{CBF}\left(\mathrm{ml} \mathrm{hg}^{-1} \mathrm{~min}^{-1}\right)$. Ordinate: PS products $\left(\mathrm{ml} \mathrm{hg}{ }^{-1} \mathrm{~min}^{-1}\right)$. Absent correlation is consistent with incomplete flow-limitation of blood-brain transfer of $\left[{ }^{11} \mathrm{C}\right] \mathrm{PiB}$.

The relations among the clearance and extraction estimates and the measured flow values are illustrated in Figure 8. The similar regional PS-products in the two groups explain the numerically attenuated and hence insignificant differences between the extraction fractions. Thus, the comparatively low PS-products are consistent with extraction fractions that do not change very significantly with changing blood flow rates, as shown in Figure 9.

The information that can be gleaned from the $\left[{ }^{11} \mathrm{C}\right] \mathrm{PiB}$ uptake clearly depends on when the uptake is determined. After $10 \mathrm{~min}$ of circulation, among the two groups, the retention of $\left[{ }^{11} \mathrm{C}\right] \mathrm{PiB}$ and its possible metabolites differed significantly for the frontal lobe and cerebral cortex, but not for the gray matter of the cerebellum. In the cortical regions, the uptake of $\left[{ }^{11} \mathrm{C}\right] \mathrm{PiB}$ in the patients with Alzheimer's disease exceeded that of the healthy controls by $40-50 \%$, indicating $\left[{ }^{11} \mathrm{C}\right] \mathrm{PiB}$ retention at this time. For the cerebellum, the accumulation of $\left[{ }^{11} \mathrm{C}\right] \mathrm{PiB}$ did not differ between the two groups, as shown in Figure 10. From 1 to $4 \mathrm{~min}$ of circulation, the brain uptake of $\left[{ }^{11} \mathrm{C}\right] \mathrm{PiB}$ relative to

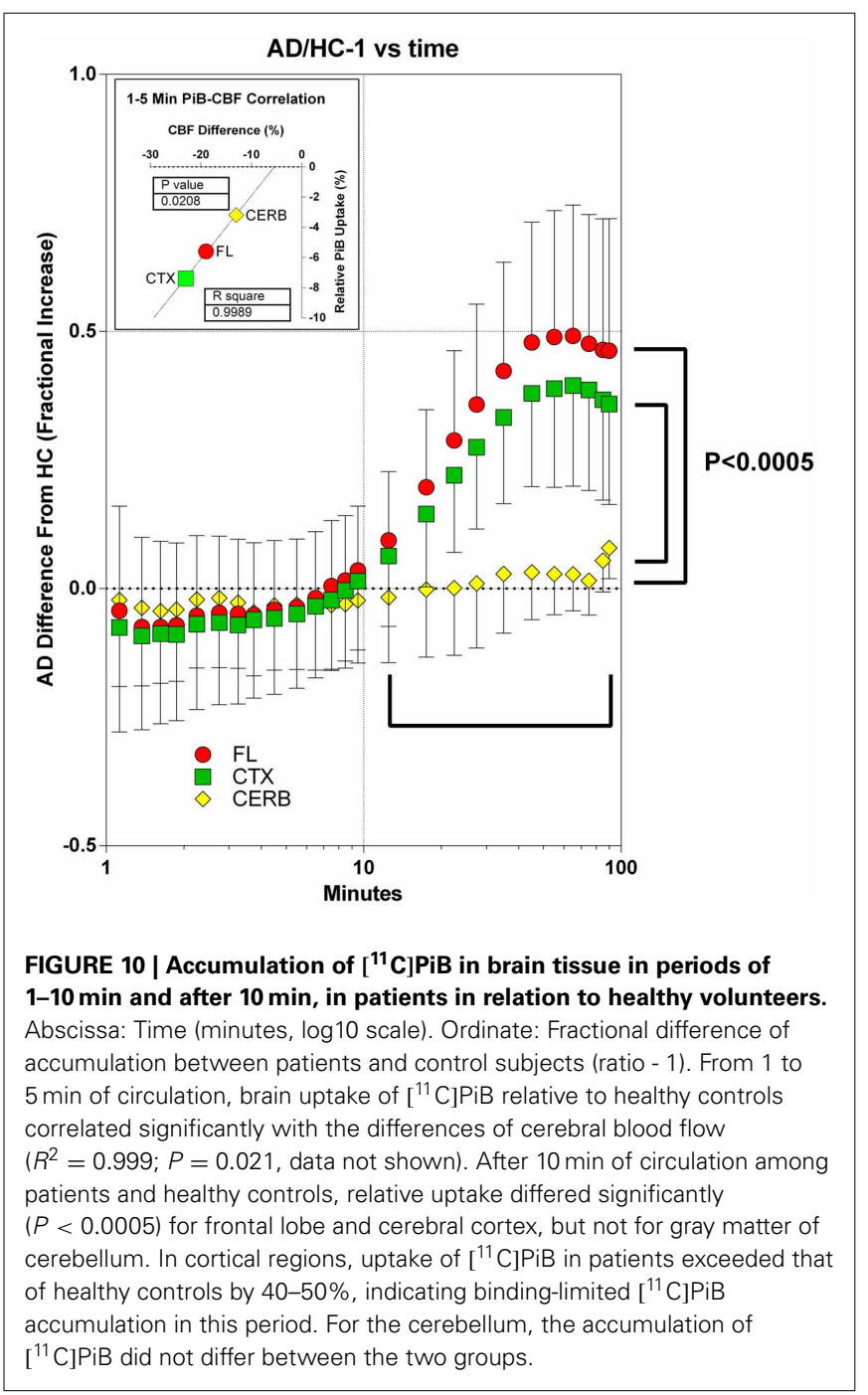


healthy controls correlated significantly with the differences of cerebral blood flow $\left(R^{2}=0.999 ; P=0.021\right)$, indicating the partially flow-limited uptake of $\left[{ }^{11} \mathrm{C}\right] \mathrm{PiB}$ during this period shown in Figure 10.

To claim that a tracer with the properties of $\left[{ }^{11} \mathrm{C}\right] \mathrm{PiB}$, with an average extraction fraction of $0.53 \pm 0.10$ (SD), is useful as a flow indicator at the very least requires a careful assessment of the variability of the results and the potential errors that may arise. In the present study, the correlation coefficient of measured and calculated flow values was $R^{2}=0.20$ with a significance of $P<0.01$ and a slope of $58 \%$ of the line of identity for a total of 33 comparisons ( 3 brain regions from 11 subjects each).

\section{ACKNOWLEDGMENTS}

The authors wish to acknowledge the support of Aarhus University, the Lundbeck Foundation, the Danish National Science Foundation, the Center of Healthy Aging Research, University of Copenhagen, and the Danish Council of Independent Research.

\section{REFERENCES}

Aanerud, J., Borghammer, P., Chakravarty, M. M., Vang, K., Rodell, A. B., Jónsdottir, K. Y., et al. (2012). Brain energy metabolism and blood flow differences in healthy aging. J. Cereb. Blood Flow Metab. 32, 1177-1187. doi: 10.1038/jcbfm.2012.18

Blomqvist, G. (1984). On the construction of functional maps in positron emission tomography. J. Cereb. Blood Flow Metab. 4, 629-632. doi: 10.1038/jcbfm. 1984.89

Blomqvist, G., Engler, H., Nordberg, A., Ringheim, A., Wall, A., Forsberg, A., et al. (2008). Unidirectional influx and net accumulation of PIB. Open Neuroimag J. 2, 114-125. doi: 10.2174/1874440000802010114

Collins, D. L., and Evans, A. C. (1997). Animal: validation and applications of nonlinear registration-based segmentation. Int. J. Pattern Recognit. Artif. Intell. 11, 1271-1294. doi: 10.1142/S0218001497000597

Crone, C. (1963). The permeability of capillaries in various organs as determined by the use of the 'indicator diffusion' method. Acta Physiol. Scand. 58, 292-305. doi: 10.1111/j.1748-1716.1963.tb02652.x

Crone, C. (1965). The permeability of brain capillaries to non-electrolytes. Acta Physiol. Scand. 64, 407-417. doi: 10.1111/j.1748-1716.1965.tb04198.x

Forsberg, A., Engler, H., Blomqvist, G., Långström, B., and Nordberg, A. (2012). The use of PIB-PET as a dual pathological and functional biomarker in AD. Biochim. Biophys. Acta 1822, 380-385. doi: 10.1016/j.bbadis.2011.11.006

Gjedde, A. (1981). High- and low-affinity transport of D-glucose from blood to brain. J. Neurochem. 36, 1463-1471. doi: 10.1111/j.1471-4159.1981.tb 00587.x

Gjedde, A. (1982). Calculation of cerebral glucose phosphorylation from brain uptake of glucose analogs in vivo: a re-examination. Brain Res. 257, 237-274. doi: 10.1016/0165-0173(82)90018-2

Gjedde, A., Andersson, J., and Eklöf, B. (1975). Brain uptake of lactate, antipyrine, water and ethanol. Acta Physiol Scand. 93, 145-149. doi: 10.1111/j.17481716.1975.tb05802.x

Gjedde, A., and Christensen, O. (1984). Estimates of Michaelis-Menten constants for the two membranes of the brain endothelium. J. Cereb. Blood Flow Metab. 4, 241-249. doi: 10.1038/jcbfm.1984.33

Gjedde, A., Hansen, A. J., and Siemkowicz, E. (1980). Rapid simultaneous determination of regional blood flow and blood-brain glucose transfer in brain of rat. Acta Physiol. Scand. 108, 321-330. doi: 10.1111/j.1748-1716.1980.tb06540.x

Gjedde, A., and Wong, D. F. (2001). Quantification of neuroreceptors in living human brain. V. Endogenous neurotransmitter inhibition of haloperidol binding in psychosis. J. Cereb. Blood Flow Metab. 21, 982-994. doi: 10.1097/00004647-200108000-00011
Hardy, J., and Selkoe, D. J. (2002). The amyloid hypothesis of Alzheimer's disease: progress and problems on the road to therapeutics. Science 297, 353-336. (2002). Review. Erratum in: Science 297, 2209. doi: 10.1126/science. 1072994

Ikonomovic, M. D., Klunk, W. E., Abrahamson, E. E., Mathis, C. A., Price, J. C., Tsopelas, N. D., et al. (2008). Post-mortem correlates of in vivo PiB-PET amyloid imaging in a typical case of Alzheimer's disease. Brain 131(Pt 6), 1630-1645. doi: 10.1093/brain/awn016

Jack, C. R. Jr., Knopman, D. S., Jagust, W. J., Shaw, L. M., Aisen, P. S., Weiner, M. W., et al. (2010). Hypothetical model of dynamic biomarkers of the Alzheimer's pathological cascade. Lancet Neurol. 9, 119-128. doi: 10.1016/S1474-4422(09)70299-6

Johannsen, P., Jakobsen, J., and Gjedde, A. (2000). Statistical maps of cerebral blood flow deficits in Alzheimer's disease. Eur. J. Neurol. 7, 385-392. doi: 10.1046/j.1468-1331.2000.00088.x

Klunk, W. E., Engler, H., Nordberg, A., Wang, Y., Blomqvist, G., Holt, D. P., et al. (2004). Imaging brain amyloid in Alzheimer's disease with Pittsburgh Compound-B. Ann Neurol. 55, 306-319. doi: 10.1002/ana.20009

Lawson, G., and Hanson, R. J. (1974). Solving Least Squares Problems. New Jersey, NJ: Society for Industrial and Applied Mathematics.

Lockhart, A., Lamb, J. R., Osredkar, T., Sue, L. I., Joyce, J. N., Ye, L., et al. (2007). PIB is a non-specific imaging marker of amyloid-beta (Abeta) peptiderelated cerebral amyloidosis. Brain 130(Pt 10), 2607-2615. doi: 10.1093/brain/ awm 191

Lolk, A., Nielsen, H., Andersen, K., Andersen, J., and Kragh-Sørensen, P. (2000). CAMCOG as a screening instrument for dementia: the Odense study. Cambridge Cognitive Examination. Acta Psychiatr. Scand. 102, 331-335. doi: 10.1034/j.1600-0447.2000.102005331.x

Lopresti, B. J., Klunk, W. E., Mathis, C. A., Hoge, J. A., Ziolko, S. K., Lu, X., et al. (2005). Simplified quantification of Pittsburgh Compound B amyloid imaging PET studies: a comparative analysis. J. Nucl. Med. 46, 1959-1972.

McKhann, G. M., Knopman, D. S., Chertkow, H., Hyman, B. T., Jack, C. R. Jr., Kawas, C. H., et al. (2011). The diagnosis of dementia due to Alzheimer's disease: recommendations from the National Institute on Aging-Alzheimer's Association workgroups on diagnostic guidelines for Alzheimer's disease. Alzheimers Dement. 7, 263-269. doi: 10.1016/j.jalz.2011.03.005

Mintun, M. A., Larossa, G. N., Sheline, Y. I., Dence, C. S., Lee, S. Y., Mach, R. H., et al. (2006). [11C]PIB in a nondemented population: potential antecedent marker of Alzheimer disease. Neurology 67, 446-452. doi: 10.1212/01.wnl.0000228230.26044.a4

Ohta, S., Meyer, E., Fujita, H., Reutens, D. C., Evans, A., and Gjedde, A. (1996). Cerebral [15O]water clearance in humans determined by PET: I. Theory and normal values. J. Cereb. Blood Flow Metab. 16, 765-780. doi: 10.1097/00004647199609000-00002

Ohta, S., Meyer, E., Thompson, C. J., and Gjedde, A. (1992). Oxygen consumption of the living human brain measured after a single inhalation of positron emitting oxygen. J. Cereb. Blood Flow Metab. 12, 179-192. doi: 10.1038/jcbfm.1992.28

Patlak, C. S., Blasberg, R. G., and Fenstermacher, J. D. (1983). Graphical evaluation of blood-to-brain transfer constants from multiple-time uptake data. J. Cereb. Blood Flow Metab. 3, 1-7. doi: 10.1038/jcbfm.1983.1

Price, J. C., Klunk, W. E., Lopresti, B. J., Lu, X., Hoge, J. A., Ziolko, S. K., et al. (2005). Kinetic modeling of amyloid binding in humans using PET imaging and Pittsburgh Compound-B. J. Cereb. Blood Flow Metab. 25, 1528-1547. doi: 10.1038/sj.jcbfm.9600146

Rodell, A. B., Aanerud, J., Braendgaard, H., and Gjedde, A. (2012). Low residual CBF variability in Alzheimer's Disease after correction for $\mathrm{CO}(2)$ Effect. Front Neuroenergetics 4:8. doi: 10.3389/fnene.2012.00008

Rostomian, A. H., Madison, C., Rabinovici, G. D., and Jagust, W. J. (2011). Early 11C-PIB frames and 18F-FDG PET measures are comparable: a study validated in a cohort of AD and FTLD patients. J. Nucl. Med. 52, 173-179. doi: 10.2967/jnumed.110.082057

Sakurada, O., Kennedy, C., Jehle, J., Brown, J. D., Carbin, G. L., Sokoloff, L. (1978). Measurement of local cerebral blood flow with iodo[14C] antipyrine. Am. J. Physiol. 234, H59-H66.

Varrone, A., Sjöholm, N., Eriksson, L., Gulyás, B., Halldin, C., and Farde, L. (2009). Advancement in PET quantification using 3D-OP-OSEM point spread function 
reconstruction with the HRRT. Eur. J. Nucl. Med. Mol. Imaging 36, 1639-1650. doi: 10.1007/s00259-009-1156-3

Wong, D. F., Moghekar, A. R., Rigamonti, D., Brasic, J. R., Rousset, O., Willis, W., et al. (2013). An in vivo evaluation of cerebral cortical amyloid with [18F]flutemetamol using positron emission tomography compared with parietal biopsy samples in living normal pressure hydrocephalus patients. Mol. Imaging Biol. 15, 230-237. doi: 10.1007/s11307-012-0583-x

Conflict of Interest Statement: The authors declare that the research was conducted in the absence of any commercial or financial relationships that could be construed as a potential conflict of interest.
Received: 27 August 2013; paper pending published: 30 August 2013; accepted: 19 October 2013; published online: 07 November 2013.

Citation: Gjedde A, Aanerud J, Braendgaard H and Rodell AB (2013) Blood-brain transfer of Pittsburgh compound B in humans. Front. Aging Neurosci. 5:70. doi: 10.3389/fnagi.2013.00070

This article was submitted to the journal Frontiers in Aging Neuroscience.

Copyright () 2013 Gjedde, Aanerud, Braendgaard and Rodell. This is an openaccess article distributed under the terms of the Creative Commons Attribution License (CC BY). The use, distribution or reproduction in other forums is permitted, provided the original author(s) or licensor are credited and that the original publication in this journal is cited, in accordance with accepted academic practice. No use, distribution or reproduction is permitted which does not comply with these terms. 